\title{
Novel Complexity Indicator of Manufacturing Process Chains and Its Relations to Indirect Complexity Indicators
}

\author{
Vladimir Modrak and Zuzana Soltysova \\ Faculty of Manufacturing Technologies, Technical University of Kosice, Bayerova 1, 08001 Presov, Slovakia \\ Correspondence should be addressed to Vladimir Modrak; vladimir.modrak@tuke.sk
}

Received 24 February 2017; Accepted 10 May 2017; Published 21 June 2017

Academic Editor: Dimitri Volchenkov

Copyright ( 2017 Vladimir Modrak and Zuzana Soltysova. This is an open access article distributed under the Creative Commons Attribution License, which permits unrestricted use, distribution, and reproduction in any medium, provided the original work is properly cited.

\begin{abstract}
Manufacturing systems can be considered as a network of machines/workstations, where parts are produced in flow shop or job shop environment, respectively. Such network of machines/workstations can be depicted as a graph, with machines as nodes and material flow between the nodes as links. The aim of this paper is to use sequences of operations and machine network to measure static complexity of manufacturing processes. In this order existing approaches to measure the static complexity of manufacturing systems are analyzed and subsequently compared. For this purpose, analyzed competitive complexity indicators were tested on two different manufacturing layout examples. A subsequent analysis showed relevant potential of the proposed method.
\end{abstract}

\section{Introduction}

There is no doubt that manufacturing systems are one of the most complex processes. Moreover, the complexity has a tendency to increase due to dynamic changes in global market environment. For example, growing demand for customized products motivates companies to implement a transition toward a mass-customized manufacturing. According to Blecker et al. [1] mass customization induces a high complexity level in a context of various customer requirements and a steadily changing environment. There can be a positive side resulting from high complexity, but usually it brings negative long-term consequences to the business survival. Therefore, an investigation of complexity manufacturing process chains helps to understand and control the nonlinear behaviour of manufacturing systems [2]. Fredendall and Gabriel [3] in this context point out that by "measuring the system's complexity, the managers can identify problems in the system that are hindering the production flow." Isik [4] specifies other negative consequences of complexity related to logistics activities as high operational costs, customer dissatisfaction, time delay in delivery, excess inventory, or inventory shortage. In general, complexity is not easy to measure, since it is difficult to define precisely. Obviously, there are many useful complexity definitions related to manufacturing systems (see, e.g., [59]). In addition, several approaches were proposed during the past decades to analyze the manufacturing complexity. Those approaches differ especially in terms of types of complexity. There are two basic types of complexity in relation to the domain of the application: physical and functional [10]. The complexity viewed in terms of functional domain is defined as a measure of uncertainty in achieving the functional requirements. In the physical domain, manufacturing complexity is frequently classified into two types, static and dynamic. Dynamic complexity can be, in simplified manner, defined as uncertainty of the manufacturing system's behaviour in a certain time period [11]. Static complexity is characterized as a function of the structure of the system [12]. Due to the fact that description of dynamic behaviour of manufacturing systems would require establishing complicated analytical equations, more extensive effort was made to develop static complexity metrics. Nevertheless, the debate on the effectiveness of the static complexity measures is still alive. The reason lies in the fact that static models of manufacturing process chains are generated for several purposes, for which different optimality criteria are specified. Moreover, some indicators of the static complexity can be seen as more or less alternative measures and other ones allow reflecting 
only specific properties of manufacturing process models. The main challenge in the complexity metric is to increase their effectiveness by getting a better appreciation of the real problems that manufacturers often encounter. Achieving this objective was the main motivation of the presented research to develop the novel method to measure the static complexity by using Shannon information theory.

\section{Related Work}

Firstly, it is useful to provide a working definition of complex system to specify a context in which this article focuses on the issues. We understand complex system as "a system with numerous components and interconnections, interactions or interdependencies that are difficult to describe, understand, predict, manage, design, and/or change" [13]. This definition inherently assumes that complexity of such systems arises not only from the size of the system but also from the interrelationships of the system components and the unpredictable behaviour of its drivers.

Basically, there are two approaches to constructing complexity measures of manufacturing systems: algorithmic and probabilistic. Algorithmic complexity is object of study in algorithmic information theory and is based on the idea that simple tasks can be done by short algorithm while complex tasks require long computer programs [14]. The probabilistic approach to complexity is analyzing the system's regularities as a basis for determining complexity [15]. The probabilistic approach can be divided into entropy-based complexity measures and axiomatic design-based complexity measures. In axiomatic design theory, the design process is described in terms of the mapping between four domains: the customer domain, the functional domain, the physical domain, and the process domain. Accordingly, complexity is defined as a measure of uncertainty in achieving the specified functional requirements derived from customer needs [16].

The most accepted methods for complexity measures are related to information theory of entropy. The entropy is commonly associated with the amount of order, disorder, or chaos in a thermodynamic system and was first introduced by Clausius [17]. Later it was studied from statistical aspect mainly by Shannon [18]. The entropy-based complexity measure for manufacturing process chains was first adapted and introduced by Frizelle and Woodcock [19]. Complexity in another view is characterized as the number of system elements and relations among them (see, e.g., [20, 21]). Suh [22] confirmed that the manufacturing design complexity may also be seen in terms of variability, disorder, uncertainty, or entropy and proposed early complexity measurement for product design stages. Frizelle and Richards [23] proposed so-called dynamic entropy model divided into structural complexity and operational complexity. Fujimoto et al. [24] proposed an information entropy-based measure of complexity for assembly planning. More recently, Hu et al. [25] applied entropy function to quantify the complexity of manufacturing processes and their configurations with examples in machining processes. Elmaraghy et al. [26] developed a set of complexity indices to compare layout alternatives at early design stages. Zhang [27] focuses on modelling static entropy-based complexity in manufacturing systems. His approach provides insight into the inherent complexity of system components and structure. Fisher et al. [28] pointed out that when looking downstream, uncertainties in demand variability create problems in planning, scheduling, and control. Entropy-based approaches to manufacturing complexity were presented in papers by Sivadasan et al. [29] and Deshmukh Abhijit [30]. Based on this theoretical background, complexity is considered as a random variable with different states and corresponding probabilities for each state. Isik [31] presented quite similar approach to operational complexity in manufacturing considering actual and scheduled demand using a deviation of outcomes from the expected outcome value for a definition of state's intervals.

From drivers' point of view, internal and external complexity are mainly considered [32-34]. According to Serdarasan [35] complexity drivers are more or less manageable. Anderson [36] noted that organizational complexity has been traditionally viewed as a structural variation rate. The concept of complexity has also been treated in manufacturing research by analyzing operations processes (see, e.g., $[6,37,38])$. Several research works were conducted on a relation between complexity and manufacturing strategy [39-41].

Inspired from the mentioned literature, our approach presented in this paper is complementary to the approaches mentioned above.

\section{Description of Existing Metrics to Measure Static Complexity}

In order to identify differences between the proposed method and existing metrics, three similar metrics will be further described and mutually compared including the proposed one. The first of these methods is developed by Deshmukh [12], who comprehensively defined the term static complexity of manufacturing systems and determined avoidable properties of static complexity metrics.

3.1. Metric by Deshmukh. He developed for this purpose three static complexity measures that differ in numbers of input variables. The first of them includes only number of machines; the second one incorporates number of operations and number of parts. The last of them is dedicated for flexible manufacturing systems assuming that the flexible manufacturing systems have the maximum entropy caused by multiple types of parts $n$, operations $m$, and machines $r$. Then, the maximum static complexity can be expressed as follows [12]:

$$
H_{s}=\log m^{2} n r .
$$

As an example, if we consider manufacturing system consisting of 5 machines, 10 operations, and 20 parts, then static complexity of manufacturing system using (1) equals 4 bits.

Moreover, he defined significant properties of static complexity measures. According to him, any static complexity measure should be able to satisfy the following conditions. 
Rule \#1. Static complexity should increase with the number of parts and number of machines and operations required to process the part mix.

Rule \#2. Static complexity should increase with increase in sequence flexibility for the parts in the production batch.

Rule \#3. Static complexity should increase as sharing of resources by parts increases.

Rule \#4. If the original part mix is split into two or more groups, then the complexity of processing should remain constant.

These rules will be further used to validate presented metrics whether they follow the conditions or not.

3.2. Metric by Frizelle. The metric proposed by him adopts the concept of Shannon's information entropy. Its mathematical expression can be formulated in simple way as [18]

$$
H_{s}=-\sum_{i=1}^{S} p_{i} \cdot \log _{2} p_{i},
$$

where $S$ represents the number of possible states the system can be in and $p_{i}$ is probability of system being in state $i$.

The principle of his method is based on relation between products and machines according to the scheduled plan. So, the previous equation (2) was modified as follows [38]:

$$
H_{S}=-\sum_{j=1}^{M} \sum_{i=1}^{S} p_{i j} \log _{2} p_{i j},
$$

where $M$ represents the number of machines, $S$ is the number of possible planned states the machine $j$ can be in, $p_{i j}$ is probability that the machine $j$ is in state $i$.

As an example, let us have the manufacturing system produce only one part with one machine. Then, probability of machine being in working state is calculated as ratio between working time of given machine and total manufacturing lead time.

3.3. Metric by Zhang. Zhang [42] proposed measuring static complexity of manufacturing systems using Shannon's information entropy [22]. In his complexity model it is assumed that probabilities of any machine $j$ being in any state $i$ are those that reflect number of operations on available machines. Accordingly, he modified (2) as follows:

$$
H_{s}=-\sum_{j=1}^{M} \sum_{i=1}^{S_{j}} p_{i j} \log _{2} p_{i j},
$$

where $M$ is the number of machines, $S_{j}$ represents the number of possible planned states the machine $j$ can be in (increased by one scheduled idle state), and $p_{i j}$ is probability of any machine $j$ being in any state $i$.

3.4. The Proposed Metric. The proposed method to quantify static complexity measures of manufacturing process is equally based on Shannon's information theory. We adopt (2) by changing a meaning of probabilities of machine states in the following way:

$$
H_{s}=-\sum_{j=1}^{M} \sum_{k=1}^{P} p_{j k} \cdot \log _{2} p_{j k},
$$

where $p_{j k}$ is probability that part $k$ is being processed on an individual machine $j$ according to scheduling order, $P$ represents the number of parts produced in manufacturing process chain (MPC), and $M$ is the number of all machines of all types.

Moreover, the following is assumed:

(1) Machines in a given manufacturing process chains are organized in serial and/or parallel manner. Then, probability that part $k$ is being processed on an individual machine $j$ is calculated in the following way. When a part is processed on machines in serial manner, then $p_{j k}$ equals $1 / M_{s}$, where $M_{s}$ is number of machines organized in serial manner. If a part is processed on machines in parallel manner, then $p_{j k}=$ $1 / M_{p}$, where $M_{p}$ is number of machines organized in parallel. In case we have serial/parallel arrangement of machines and a part is processed on one of the parallel machines, then $p_{j k}$ equals $1 / M_{s} \cdot M_{p}$.

(2) If there are identical MPCs (the same type and number of machines producing the same type and amount of parts), then static complexity of manufacturing system is calculated only for one MPC by the proposed method.

To show applicability of the indicator, the following example can be used (see Figure 1). We have serial/parallel arrangement of machines processing one part $\mathrm{P}$.

Then, probabilities $p_{j k}$ that the part is being processed by machines $M_{j}$ can be calculated as shown in Figure 2.

When the methods described above are mutually compared from the viewpoint of mechanism design, then some significant differences are identified (see in Table 1).

As it can be seen from Table 1, the proposed method seems to be the most comprehensive instrument to measure static complexity of manufacturing systems. In spite of the previous methods, this method includes parts scheduling. It takes into account the probability of parts being processed on individual machine according to scheduling order.

\section{Testing of Described Metrics}

As metric by Deshmukh is already verified, the three other metrics will be tested by the above described rules using the theoretical examples shown in Figures 3-8. Prior to testing, we will assume also operation time (set in 10 minutes), since metric by Frizelle needs to know this item.

4.1. Testing Complexity Indicators by Rule \#1. First, let us denote value of static complexity for MPC with $j$ machines and $k$ parts as $H_{j, k}$. 
TABLE 1: Mutual comparison of static complexity methods.

\begin{tabular}{lcccccc}
\hline $\begin{array}{l}\text { Static complexity } \\
\text { metrics }\end{array}$ & $\begin{array}{c}\text { Number of } \\
\text { machines }\end{array}$ & Number of parts & $\begin{array}{c}\text { Number of } \\
\text { operations }\end{array}$ & Flexible routings & $\begin{array}{c}\text { Workplace } \\
\text { organization }\end{array}$ & $\begin{array}{c}\text { Part scheduling } \\
\text { Metric by }\end{array}$ \\
Deshmukh & $\checkmark$ & $\checkmark$ & $\checkmark$ & $\mathrm{x}$ & $\mathrm{x}$ & $\mathrm{x}$ \\
Metric by Frizelle & $\checkmark$ & $\checkmark$ & $\checkmark$ & $\checkmark$ & $\checkmark$ & $\mathrm{x}$ \\
Metric by Zhang & $\checkmark$ & $\checkmark$ & $\checkmark$ & $\checkmark$ & $\checkmark$ & $\checkmark$ \\
Proposed metric & $\checkmark$ & $\checkmark$ & $\checkmark$ & $\checkmark$ & $\checkmark$ \\
\hline
\end{tabular}

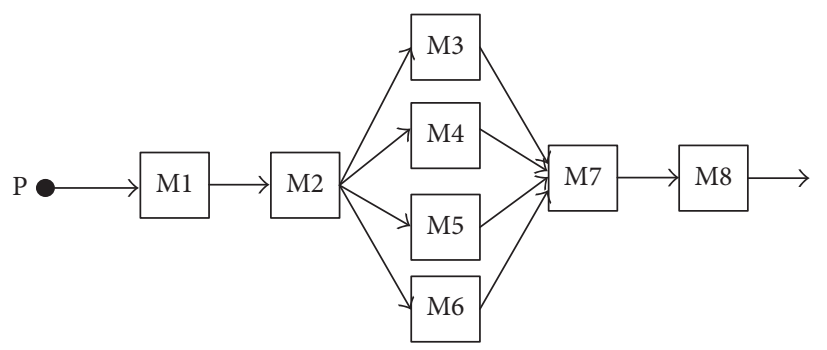

FIGURE 1: Serial/parallel arrangement of machines processing one part.

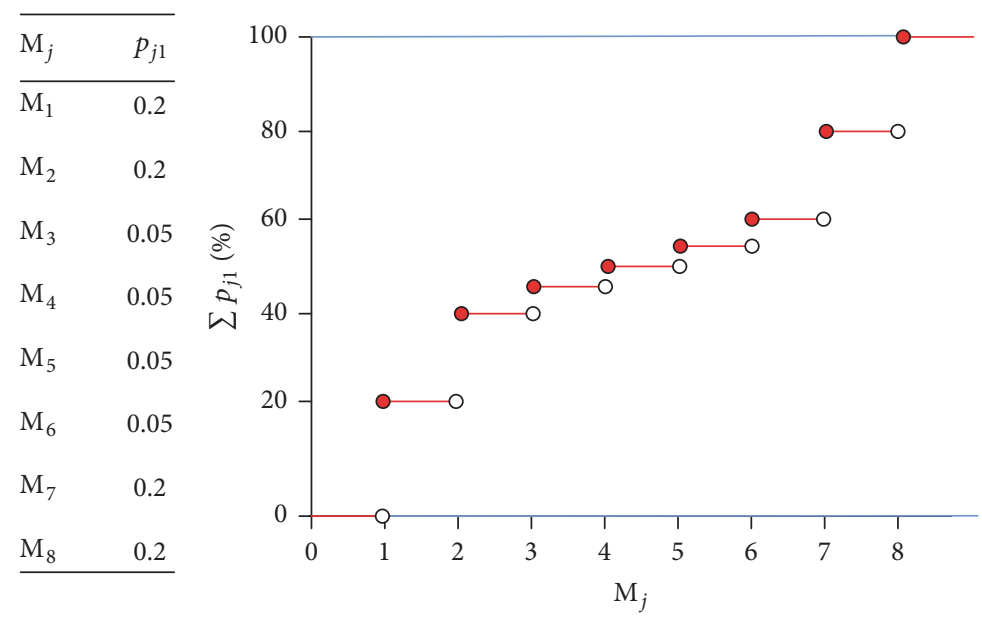

FIGURE 2: Values of probabilities $p_{j k}$ and their distribution function.

The rule is proposing (in case of the three metrics) two conditional statements:

(I) If $k$ is constant, $j$ is increasing and machines are arranged only in serial manner and then $H_{j-1, k}<$ $H_{j, k}$.

(II) If $j$ is constant, $k$ is increasing and machines are arranged only in serial manner and then $H_{j, k-1}<$ $H_{j, k}$.

4.1.1. Testing of Statement I for the 3 Complexity Metrics. Let us test two MPCs shown in Figure 3 with static complexities $H_{1 ; 1}$ and $H_{2 ; 1}$.

Applying (3), (4), and (5), according to metrics by Frizelle and Zhang and the proposed approach, we obtain the results shown in Table 2.
TABLE 2: Static complexity values and their proof.

\begin{tabular}{lccc}
\hline Complexity & $\begin{array}{c}\text { Metric by } \\
\text { Frizelle }\end{array}$ & $\begin{array}{c}\text { Metric by } \\
\text { Zhang }\end{array}$ & Proposed metric \\
\hline$H_{1 ; 1}$ & 0 bits & 1 bit & 0 bits \\
$H_{2 ; 1}$ & 1 bit & 2 bits & 1 bit \\
Proof & $H_{2,1}>H_{1,1}$ & $H_{2,1}>H_{1,1}$ & $H_{2,1}>H_{1,1}$ \\
\hline
\end{tabular}

For example, the complexities according to the proposed metric are calculated using (5) as follows:

$$
\begin{aligned}
H_{1,1} & =-p_{1,1} \log _{2} p_{1,1}=-1 \log _{2} 1=0 \text { bits } \\
H_{2,1} & =-p_{1,1} \log _{2} p_{1,1}+\left(-p_{2,1} \log _{2} p_{2,1}\right)=0,5+0,5 \\
& =1 \text { bit. }
\end{aligned}
$$




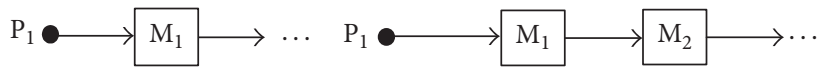

(a)

(b)

FIGURE 3: MPC consisting of (a) one machine and one part and (b) two machines and one part.

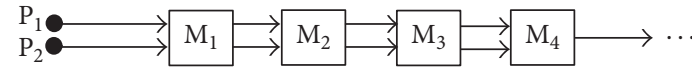

(a)

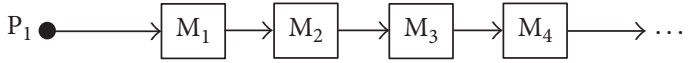

(b)

FIGURE 4: MPC consisting of (a) four machines and two parts and (b) four machines and one part.

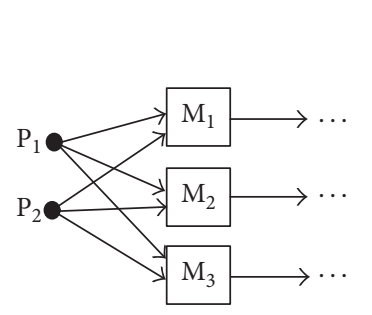

(a)

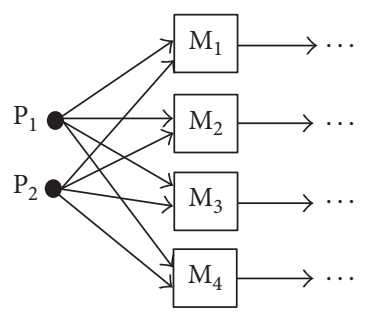

(b)

FIGURE 5: MPC consisting of (a) three machines and two parts and (b) four machines and two parts.

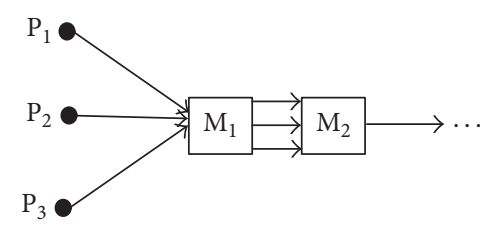

(a)

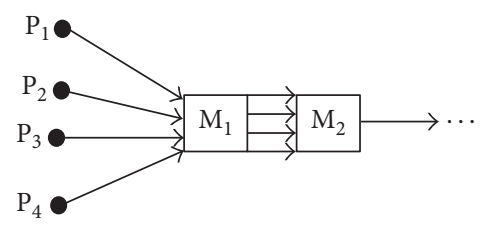

(b)

FIGURE 6: MPC consisting of (a) two machines and three parts and (b) two machines and four parts.

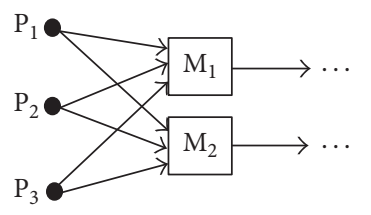

(a)

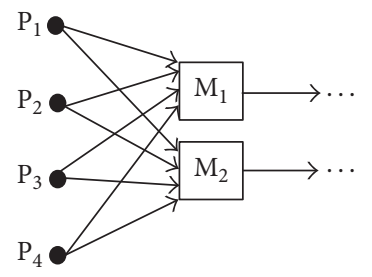

(b)

FIgURE 7: MPC consisting of (a) two machines and three parts and (b) two machines and four parts.

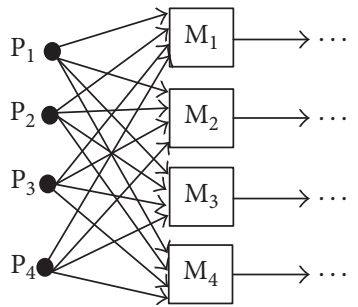

(a)

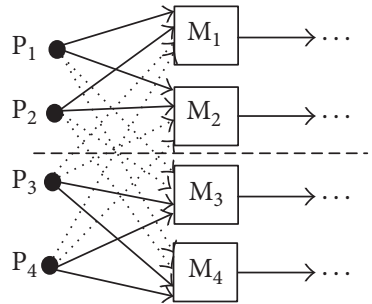

(b)

FIGURE 8: MPC consisting of (a) two machines and four parts and (b) two machines and four parts divided into two groups with one machine and two parts for one group. 
TABLE 3: Static complexity values and their proof.

\begin{tabular}{lccc}
\hline Complexity & $\begin{array}{c}\text { Metric by } \\
\text { Frizelle }\end{array}$ & $\begin{array}{c}\text { Metric by } \\
\text { Zhang }\end{array}$ & Proposed metric \\
\hline$H_{4 ; 1}$ & 2 bits & 4 bits & 2 bits \\
$H_{4 ; 2}$ & 1,89 bits & 6,34 bits & 4 bits \\
Proof & $H_{4,2}<H_{4,1}$ & $H_{4,2}>H_{4,1}$ & $H_{4,2}>H_{4,1}$ \\
\hline
\end{tabular}

TABLE 4: Proofs of Rule \#1.

\begin{tabular}{lcc}
\hline Complexity indicator & $\begin{array}{c}\text { Proofs for } \\
\text { Rule \#1 (a) }\end{array}$ & $\begin{array}{c}\text { Proofs for } \\
\text { Rule \#1 (b) }\end{array}$ \\
\hline Metric by Frizelle & True & False \\
Metric by Zhang & True & True \\
Proposed metric & True & True \\
\hline
\end{tabular}

TABLE 5: Static complexity values and their proof.

\begin{tabular}{lccc}
\hline Complexity & $\begin{array}{c}\text { Metric by } \\
\text { Frizelle }\end{array}$ & $\begin{array}{c}\text { Metric by } \\
\text { Zhang }\end{array}$ & Proposed metric \\
\hline$H_{3 ; 2}$ & 1,5 bits & 4,75 bits & 2,86 bits \\
$H_{4 ; 2}$ & 1,89 bits & 6,34 bits & 4 bits \\
Proof & $H_{4,2}>H_{3,2}$ & $H_{4,2}>H_{3,2}$ & $H_{4,2}>H_{3,2}$ \\
\hline
\end{tabular}

TABle 6: Proofs of Rule \#2.

\begin{tabular}{lc}
\hline Complexity indicator & Proofs for Rule \#2 \\
\hline Metric by Frizelle & True \\
Metric by Zhang & True \\
Proposed metric & True \\
\hline
\end{tabular}

4.1.2. Testing of Statement II for the 3 Complexity Metrics. Let us test two MPCs shown in Figure 4 with static complexities $H_{4 ; 2}$ and $H_{4 ; 1}$.

Applying (3), (4), and (5), according to metrics by Frizelle and Zhang and the proposed approach, we obtain the results shown in Table 3.

Summarily, the results of the proofs are depicted in Table 4.

4.2. Testing Complexity Indicators by Rule \#2. The rule proposes the following conditional statement:

If $k$ is constant, $j$ is increasing and machines are arranged only in parallel manner and then $H_{j-1, k}<$ $H_{j, k}$.

Let us test two MPCs shown in Figure 5 with static complexities $H_{3 ; 2}$ and $H_{4 ; 2}$.

Applying (3), (4), and (5), according to metrics by Frizelle and Zhang and the proposed approach, we obtain the results shown in Table 5.

The results of the proofs are summarized in Table 6.

4.3. Testing Complexity Indicators by Rule \#3. The rule is proposing two conditional statements:
TABLE 7: Static complexity values and their proof.

\begin{tabular}{lccc}
\hline Complexity & $\begin{array}{c}\text { Metric by } \\
\text { Frizelle }\end{array}$ & $\begin{array}{c}\text { Metric by } \\
\text { Zhang }\end{array}$ & Proposed metric \\
\hline$H_{2 ; 3}$ & 1 bit & 4 bits & 3 bits \\
$H_{2 ; 4}$ & 0,93 bits & 4,64 bits & 4 bits \\
Proof & $H_{2,4}<H_{2,3}$ & $H_{2,4}>H_{2,3}$ & $H_{2,4}>H_{2,3}$ \\
\hline
\end{tabular}

TABLE 8: Static complexity values and their proof.

\begin{tabular}{lccc}
\hline Complexity & $\begin{array}{c}\text { Metric by } \\
\text { Frizelle }\end{array}$ & $\begin{array}{c}\text { Metric by } \\
\text { Zhang }\end{array}$ & Proposed metric \\
\hline$H_{2 ; 3}$ & 1 bit & 4 bits & 3 bits \\
$H_{2 ; 4}$ & 0,93 bits & 4,64 bits & 4 bits \\
Proof & $H_{2,4}<H_{2,3}$ & $H_{2,4}>H_{2,3}$ & $H_{2,4}>H_{2,3}$ \\
\hline
\end{tabular}

TABle 9: Proofs of Rule \#3.

\begin{tabular}{lcc}
\hline Complexity indicator & $\begin{array}{c}\text { Proofs for } \\
\text { Rule \#3 (a) }\end{array}$ & $\begin{array}{c}\text { Proofs for } \\
\text { Rule \#3 (b) }\end{array}$ \\
\hline Metric by Frizelle & False & False \\
Metric by Zhang & True & True \\
Proposed metric & True & True \\
\hline
\end{tabular}

(I) If $j$ is constant, $k$ is increasing and machines are arranged only in serial manner and then $H_{j, k-1}<$ $H_{j, k}$.

(II) If $j$ is constant, $k$ is increasing and machines are arranged only in parallel and then $H_{j, k-1}<H_{j, k}$.

4.3.1. Testing of Statement I. Let us test two MPCs shown in Figure 6 with static complexities $\mathrm{H}_{2 ; 3}$ and $\mathrm{H}_{2 ; 4}$.

Applying (3), (4), and (5), according to metrics by Frizelle and Zhang and the proposed approach, we obtain the results shown in Table 7.

4.3.2. Testing of Statement II. Let us test two MPCs shown in Figure 7 with static complexities $\mathrm{H}_{2 ; 3}$ and $\mathrm{H}_{2 ; 4}$.

Applying (3), (4), and (5), according to metrics by Frizelle and Zhang and the proposed approach, we obtain the results shown in Table 8.

Summarization of the proof results is shown in Table 9.

4.4. Testing Complexity Indicators by Rule \#4. The proposition of this rule is as follows:

If $k$ is constant, $j$ is constant and MPC is split into two groups, and then $H_{j, k}=H_{j / 2, k}+H_{j / 2, k}$.

Let us test three MPCs shown in Figure 6 with static complexities $H_{4 ; 4}, H_{2 ; 4}$, and $H_{2 ; 4}$.

Applying (3), (4), and (5), according to metrics by Frizelle and Zhang and the proposed approach, we obtain the results shown in Table 10.

Summarily, the results of the proofs are depicted in Table 11.

The comparison showed that metrics by Deshmukh and Zhang and the proposed indicator satisfies the rules. 
TABLE 10: Static complexity values and their proof.

\begin{tabular}{lccc}
\hline Complexity & Metric by Frizelle & Metric by Zhang & Proposed Metric \\
\hline$H_{2 ; 4}$ & 0,93 bits & 4,64 bits & 4 bits \\
$H_{4 ; 4}$ & 1,85 bits & 9,28 bits & 8 bits \\
Proof & $H_{4,4}=H_{2,4}+H_{2,4}$ & $H_{4,4}=H_{2,4}+H_{2,4}$ & $H_{4,4}=H_{2,4}+H_{2,4}$ \\
\hline
\end{tabular}

TABLE 11: Proofs of Rule \#4.

\begin{tabular}{lc}
\hline Complexity indicator & Proofs for Rule \#4 \\
\hline Metric by Frizelle & True \\
Metric by Zhang & True \\
Proposed metric & True \\
\hline
\end{tabular}

However, all the metrics will be further applied on MPC layouts previously used in case studies by Zhang [42] and Yan and Irani [43]. Prior to the application, these two independent layouts and their alternatives in the subsequent section are described.

\section{Description of Compared Layouts}

Here two layout types are described in this section. The first type (Layout \#1) consists of two groups. The first group represents 3 alternatives of 2-cell design layouts and the second group is representing 2 alternatives of 3 -cell design layouts. The second type (Layout \#2) includes two alternatives of MPC, one arranged as job shop and the other as flow shop.

5.1. Layout \#1. MPC1 in Figure 9 is divided into two cells with 23 machines, where first production cell consists of 11 machines and second cell is created by 12 machines. Parts P1-P4 and P7-P11 are processed in first cell; other parts marked as P12-18 are processed only in the second cell, while parts P5 and P6 are partially processed in the second cell and finalized in the first cell.

Manufacturing process chain marked as MPC2 (see in Figure 10) is organized into two cells with 25 machines, while 16 machines are located in cell \#1 and 9 machines in cell \#2. Parts with numbers from 1 to 11 and 18 are processed in the first cell, while the remaining parts are processed in the second cell.

MPC3 in Figure 11 is similar to MPC2 with machine organization in cells, but it differs that in the second cell machine M1 is redundant and therefore removed. Parts P15 and P16 start to be produced in the first cell and they continue to the second cell for finalization.

MPC4 shown in Figure 12 contains 3 cells. Here there are 26 machines, while 8 machines are located in the first cell, 10 machines are located in the second cell, and 8 machines are located in the third cell. The first cell produces parts with numbers $1,3,7,8,9$, and 11 , while part $\mathrm{P} 3$ is finalized in the second cell. Parts P2, P4-6, P10, P15, P16, and P18 are produced in the second cell, but parts P15 and P16 are finalized in the third cell along with parts P12-14, P17, and P19.

MPC5 in Figure 13 is divided into 3 cells containing together 24 machines, where the first cell includes 5
TABLE 12: Sequence of operations for 19 parts.

\begin{tabular}{|c|c|}
\hline Part number & Sequence of operations and their times in minutes \\
\hline P1 & M1 (96), M4 (36), M8 (36), M9 (72) \\
\hline P2 & $\begin{array}{c}\text { M1 (36), M4 (120), M7 (20), M4 (120), } \\
\text { M8 (24), M7 (20) }\end{array}$ \\
\hline P3 & $\begin{array}{c}\text { M1 (96), M2 (48), M4 (36), M7 (120), } \\
\text { M8 (36), M9 (72) }\end{array}$ \\
\hline P4 & M1 (96), M4 (36), M7 (120), M9 (72) \\
\hline P5 & M1 (96), M6 (72), M10 (200), M7 (120), M9 (72) \\
\hline P6 & M6 (36), M10 (120), M7 (60), M8 (36), M9 (24) \\
\hline P7 & M6 (72), M4 (36), M8 (48), M9 (48) \\
\hline P8 & $\begin{array}{c}\text { M3 (144), M5 (120), M2 (48), M6 (72), M4 (36), } \\
\text { M8 (48), M9 (48) }\end{array}$ \\
\hline P9 & $\begin{array}{c}\text { M3 (144), M5 (120), M2 (48), M6 (72), M4 (36), } \\
\text { M8 (48), M9 (48) }\end{array}$ \\
\hline $\mathrm{P} 10$ & M4 (120), M7 (20), M4 (120), M8 (24) \\
\hline P11 & M6 (72) \\
\hline $\mathrm{P} 12$ & M11 (192), M7 (150), M12 (80) \\
\hline P13 & M11 (192), M12 (60) \\
\hline P14 & M11 (288), M7 (180), M10 (360) \\
\hline P15 & $\begin{array}{l}\text { M1 (15), M7 (70), M11 (54), M10 (45), M11 (54), } \\
\text { M12 (30) }\end{array}$ \\
\hline P16 & $\begin{array}{l}\text { M1 (15), M7 (70), M11 (54), M10 (45), M11 (54), } \\
\text { M12 (30) }\end{array}$ \\
\hline P17 & M11 (192), M7 (150), M12 (80) \\
\hline P18 & M6 (108), M7 (180), M10 (360) \\
\hline P19 & M12 (60) \\
\hline
\end{tabular}

machines, the second cell includes 15 machines, and the third cell is comprised of four machines. Parts P1, P3, P7, P8, P9, and $\mathrm{P} 11$ are produced in the first cell, while parts $\mathrm{P} 1, \mathrm{P} 3, \mathrm{P} 7$, P8, and P9 are finalized in the second cell. Parts P2, P4-6, P10, P14, P15, P16, and P18 are machined in the second cell, but parts P15 and P16 are finally produced by machines in the third cell. Remaining parts P12-13, P17, and P19 are machined only in the third cell.

Layout \#1 and its input data were taken from the chapter written by Yan and Irani [43]. These authors studied the impact of 2-cell and 3-cell design layout on MPC performance by comparing their process structure properties. This MPC produces 19 parts (P) by 12 machine types (M). Machine sequence and their operational times for all parts are in Table 12.

5.2. Layout \#2. Layout \#2 is taken from Zhang's study case [42]. Both, MPC6 for job shop and MPC7 for flow shop, consist of 20 machines of 4 types, while machining time per 


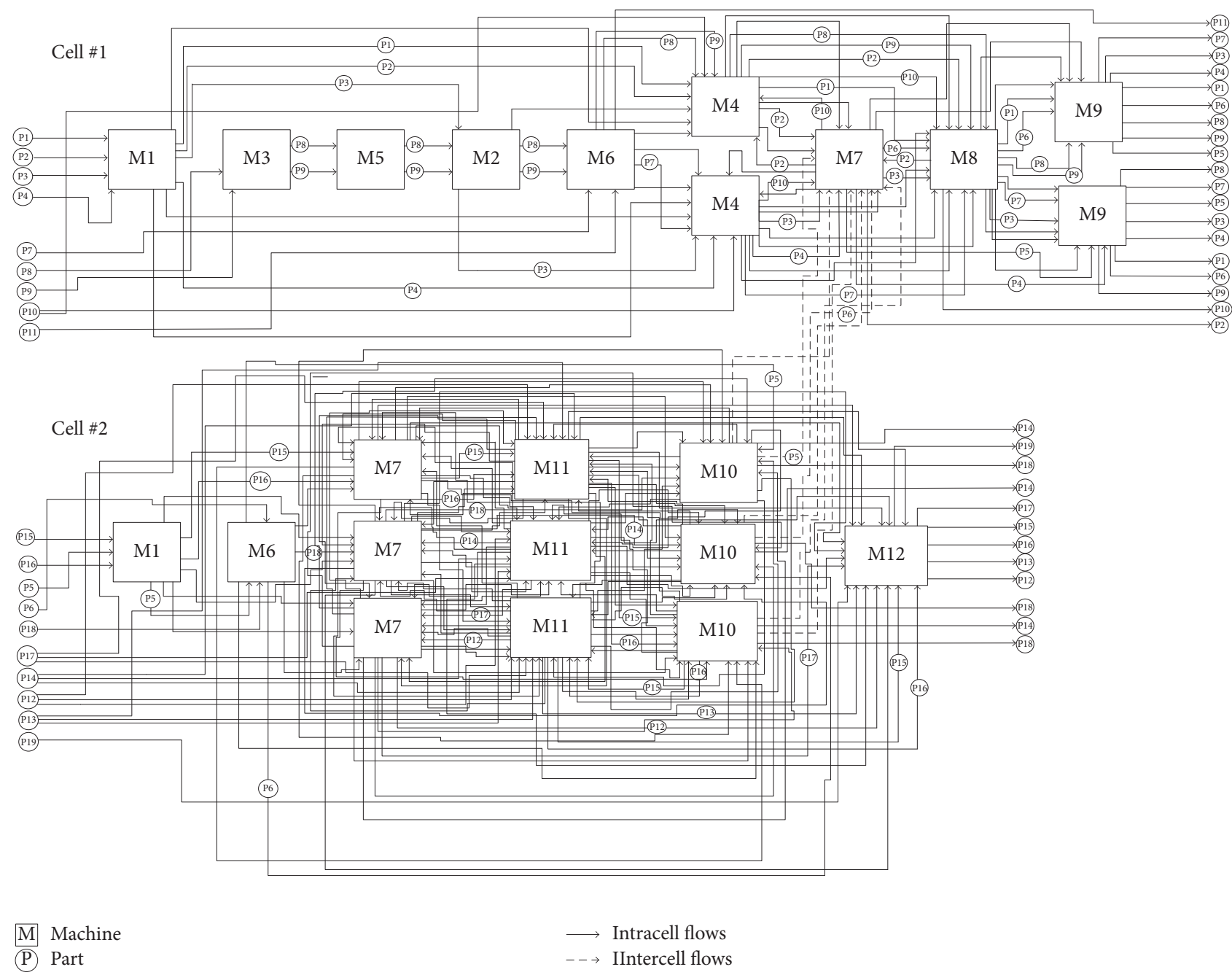

FIgURE 9: MPC1 and its part flows divided into 2 cells.

TABLE 13: Comparison of static complexity values for Layout \#1.

\begin{tabular}{lcccc}
\hline Layout \#1 & Metric by Deshmukh & Metric by Frizelle & Metric by Zhang & Proposed metric \\
\hline MPC1 & 6,45 bits & 18,6 bits & 62 bits & 47,8 bits \\
MPC2 & 6,48 bits & 17,7 bits & 65,8 bits & 50,7 bits \\
MPC3 & 6,48 bits & 17,4 bits & 60,9 bits & 53,9 bits \\
MPC4 & 6,46 bits & 21,7 bits & 61,4 bits & 44,8 bits \\
MPC5 & 6,5 bits & 19,1 bits & 57,2 bits & 47,1 bits \\
\hline
\end{tabular}

part is 10 minutes. These MPCs produce 100 products and each product passes through one of each machine type.

The first alternative of job shop production in Figure 14 is characterized by arrangement of machines of the same type by free mode.

Transformed layout, in Figure 15, into flow shop production consists of 5 lines. Every line contains four machines of each type. So, the 100 parts are regrouped into five lines, each producing 20 parts.

\section{Comparison of Performed Complexity Measures}

Calculated values of static complexity are summarized in Tables 13 and 14 for both Layouts $\# 1$ and $\# 2$ according to the four metrics.

Prior to analyses of results, one must clearly understand the desired aim of the MPC models. Therefore, the following assumptions are formulated. 

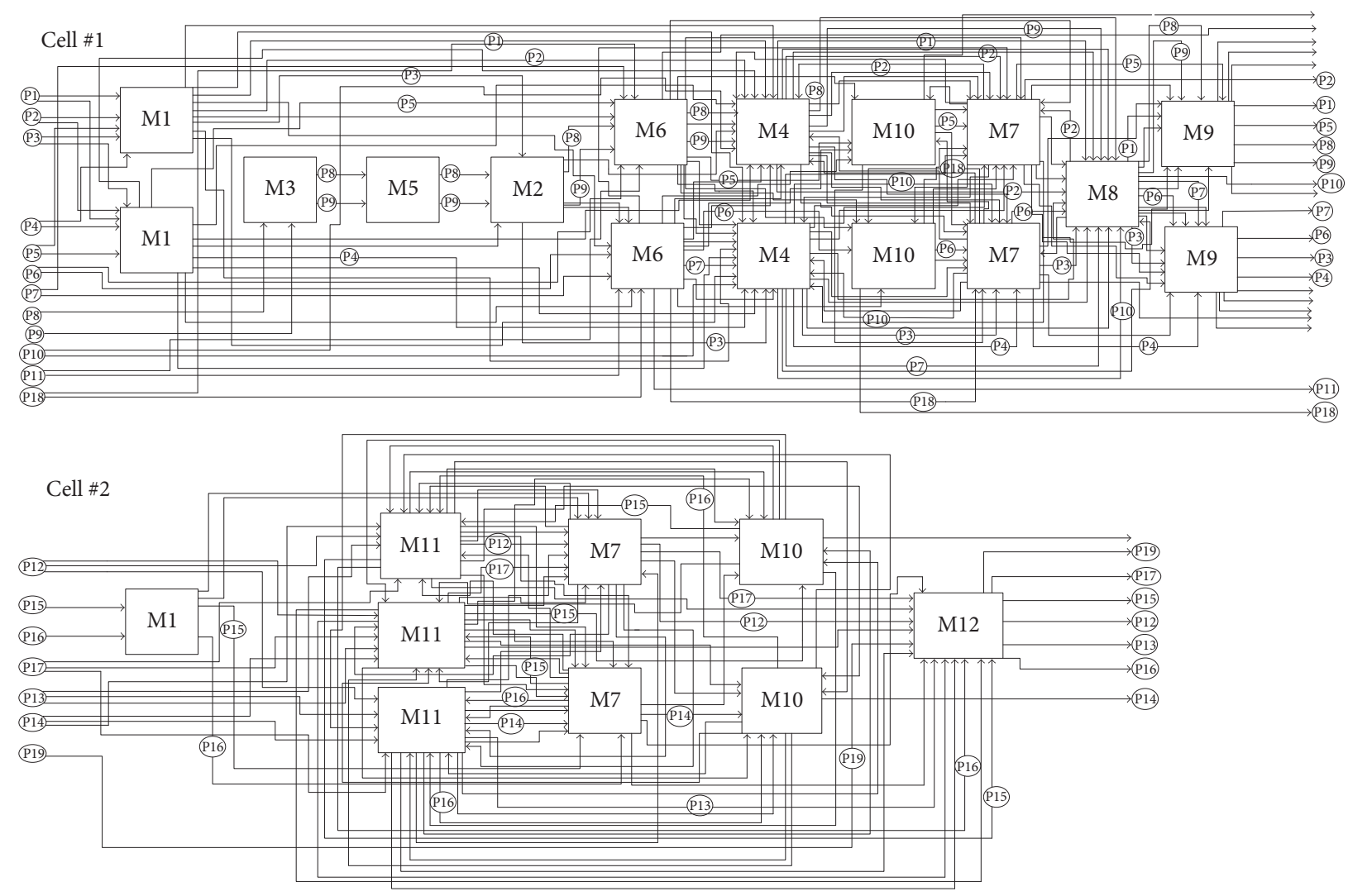
M Machine
(P) Part
$\longrightarrow$ Intracell flows
$-\rightarrow$ IIntercell flows

FIGURE 10: MPC2 and its part flows divided into 2 cells.

TABLE 14: Comparison of static complexity values for Layout \#2.

\begin{tabular}{lcccc}
\hline Layout \#2 & Metric by Deshmukh & Metric by Frizelle & Metric by Zhang & Proposed metric \\
\hline MPC6 & 7,3 bits & 10 bits & 133 bits & 4,32 bits \\
MPC7 & 7,3 bits & 10 bits & 22 bits & 2,00 bits \\
\hline
\end{tabular}

For Layout \#1, consider the following.

Assumption Number 1. It is expected that the static complexity of alternatives with three cells is lower than the static complexity of alternatives with two cells. This expectation results from the finding that "production scheduling for two cell solutions is harder than for three cell solutions" [43]. Because it is known that (see, e.g., Rintanen [44]) "harder scheduling problems typically involve uncertainty," it can be stated that harder scheduling brings more complexity to the manufacturing system than easier scheduling.

For Layout \#2, consider the following.

Assumption Number 2. The lower complexity of flow shop production is expected, compared to the job shop. This assumption is more or less generally known. For example, Morton and Pentico [45] argue that flow of parts through the
TABLE 15: Comparison of complexity indicators according to the specified assumptions.

\begin{tabular}{lcc}
\hline & $\begin{array}{c}\text { Assumption } \\
\text { Number 1 }\end{array}$ & $\begin{array}{c}\text { Assumption } \\
\text { Number 2 }\end{array}$ \\
\hline Metric by Deshmukh & $\checkmark$ & N/A \\
Metric by Frizelle & $\mathrm{x}$ & N/A \\
Metric by Zhang & $\mathrm{x}$ & $\checkmark$ \\
Novel metric & $\checkmark$ & $\checkmark$ \\
\hline
\end{tabular}

shop is usually less complex than that for closed or open job shops.

The aim of testing was to verify whether these metrics follow these tendencies. In this order, Table 15 offers the overview of how the indicators reflect the assumptions. 

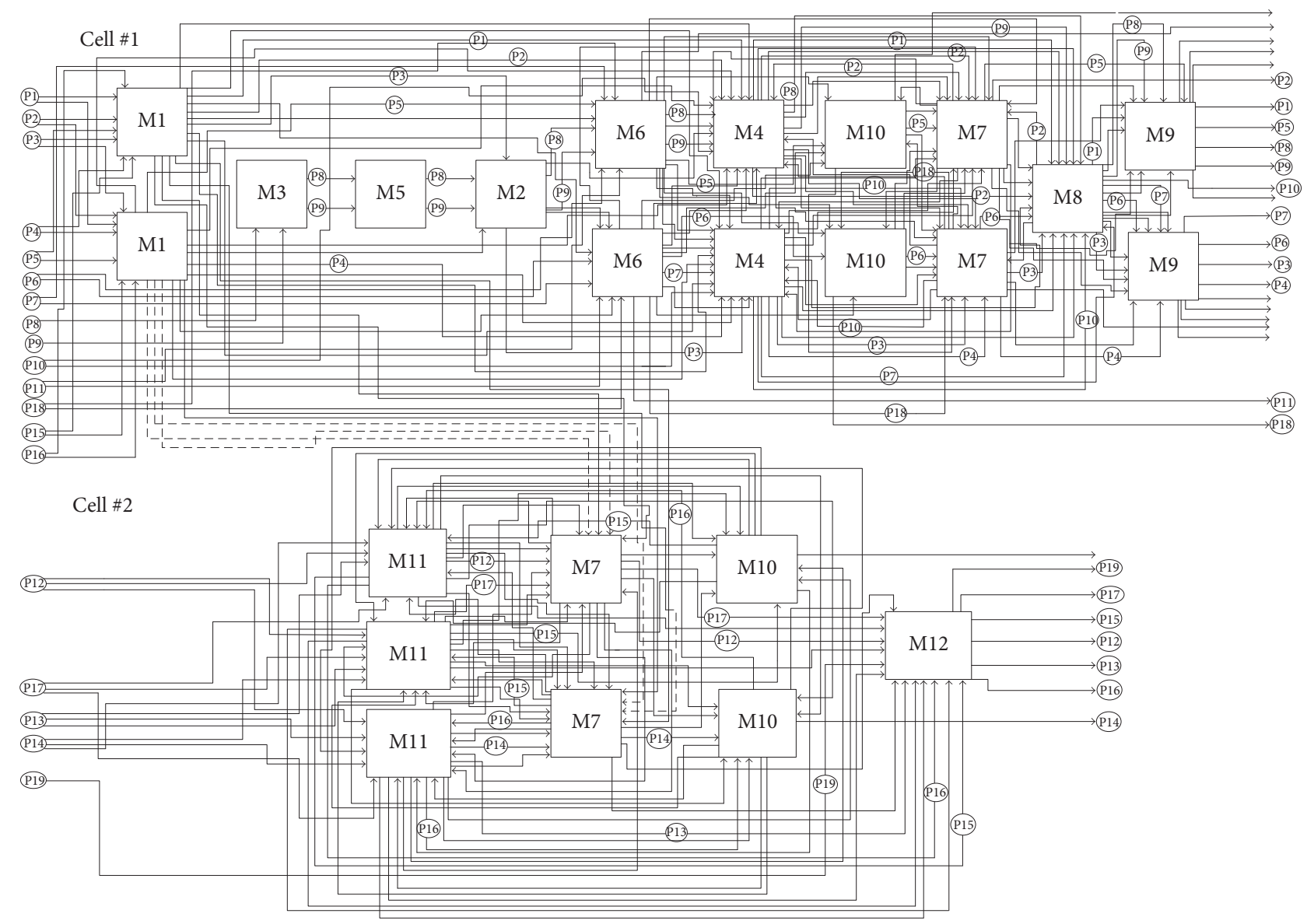

M Machine
(P) Part $\longrightarrow$ Intracell flows

$-\rightarrow$ Intercell flows

FIgURE 11: MPC3 and its part flows divided into 2 cells.

Based on the results, the tendencies by Assumption Number 1 were confirmed only by Deshmukh's metric and proposed method. The tendency by Assumption Number 2 was confirmed only by Zhang's metric and novel method, while the remaining metrics are not applicable (N/A).

\section{Comparison of the Proposed Method with Indirect Indicators}

The comparison shown above yielded positive findings about the proposed method. However, each additional verification of this metric may contribute to its objectivity or versatility. For this reason, the next section is focused on the evaluation of mutual relations between the proposed method and other indirect complexity indicators, such as the production line balancing rate and the number of intercell flows and intracell flows. For this purpose only Layout \#1 will be used.

\subsection{Description of Indirect Indicators}

7.1.1. Production Line Balancing Rate. Production line balancing rate is the quota that measures the average situation of every cycle time in working procedure on processing line. Production line balancing rate is calculated as follows [46]:

$$
P=\frac{\sum_{j=1}^{n} t_{j}}{m * \max \left(T_{i}\right)},
$$

where $t_{j}$ is the expression of standard work time of the $j$ job elements, $n$ represents the number of the work elements, $m$ is the number of total lines (cells) in MPCs, $T_{i}$ represents the work time in the line, and $\max \left(T_{i}\right)$ is the biggest line operating time.

7.1.2. Number of Intercell and Intracell Flows. Part flows of manufacturing system can be classified into intercell and intracell types. It is also known as intercell and intracell layout problems. Intercell flows are expressed as movements between the cells. Intracell flows present the connection between machines at workstations [47]. It is quite frequently stated that intercell flows impact on manufacturing system negatively [48-55]. It is due to the fact that intercell trips are difficult for scheduling and controlling. 
Cell \#1

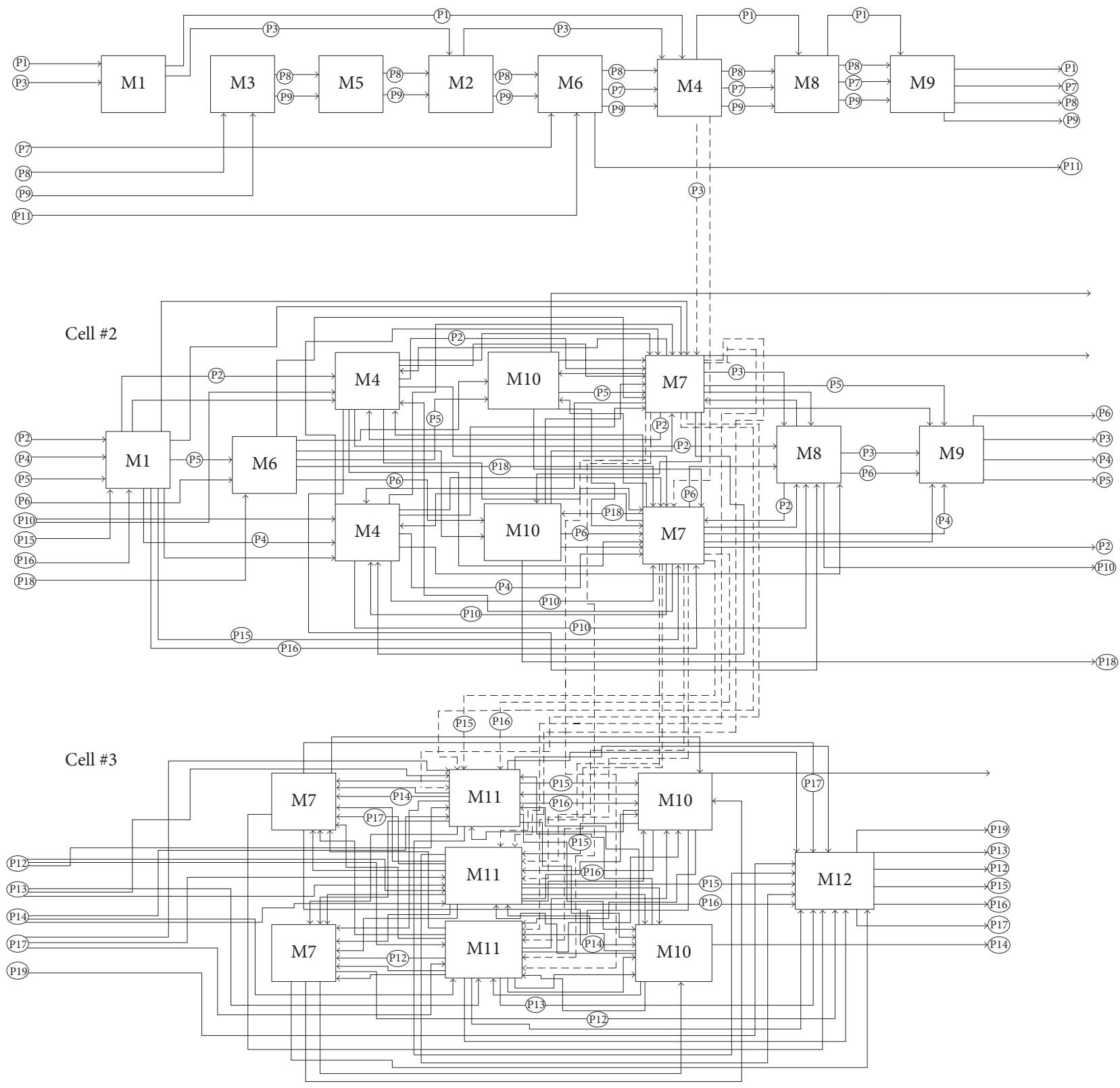

M Machine

(P) Part

$\longrightarrow$ Intracell flows

$-\rightarrow$ IIntercell flows

FigURE 12: MPC4 and its part flows divided into 3 cells.

7.2. Comparison of the Proposed Method with Indirect Complexity Indicators. The results of indirect indicators calculation are shown in Table 16.

Based on the results in Table 16 one can state that there are significant mutual relations between these indicators and static complexity. Specifically, the following prepropositions can be formulated.

Preproposition Number 1. In the case of well-balancing lines, the static complexity is lower and vice versa.
Preproposition Number 2. The greater number of intercell flows has greater impact on the static complexity than the smaller one.

Preproposition Number 3. The greater number of intracell flows has greater impact on the static complexity than the smaller one.

When verifying the prepropositions by individual MPCs we can conclude that the previous prepropositions were confirmed for all of these three indicators and for all MPCs 
Cell \#1

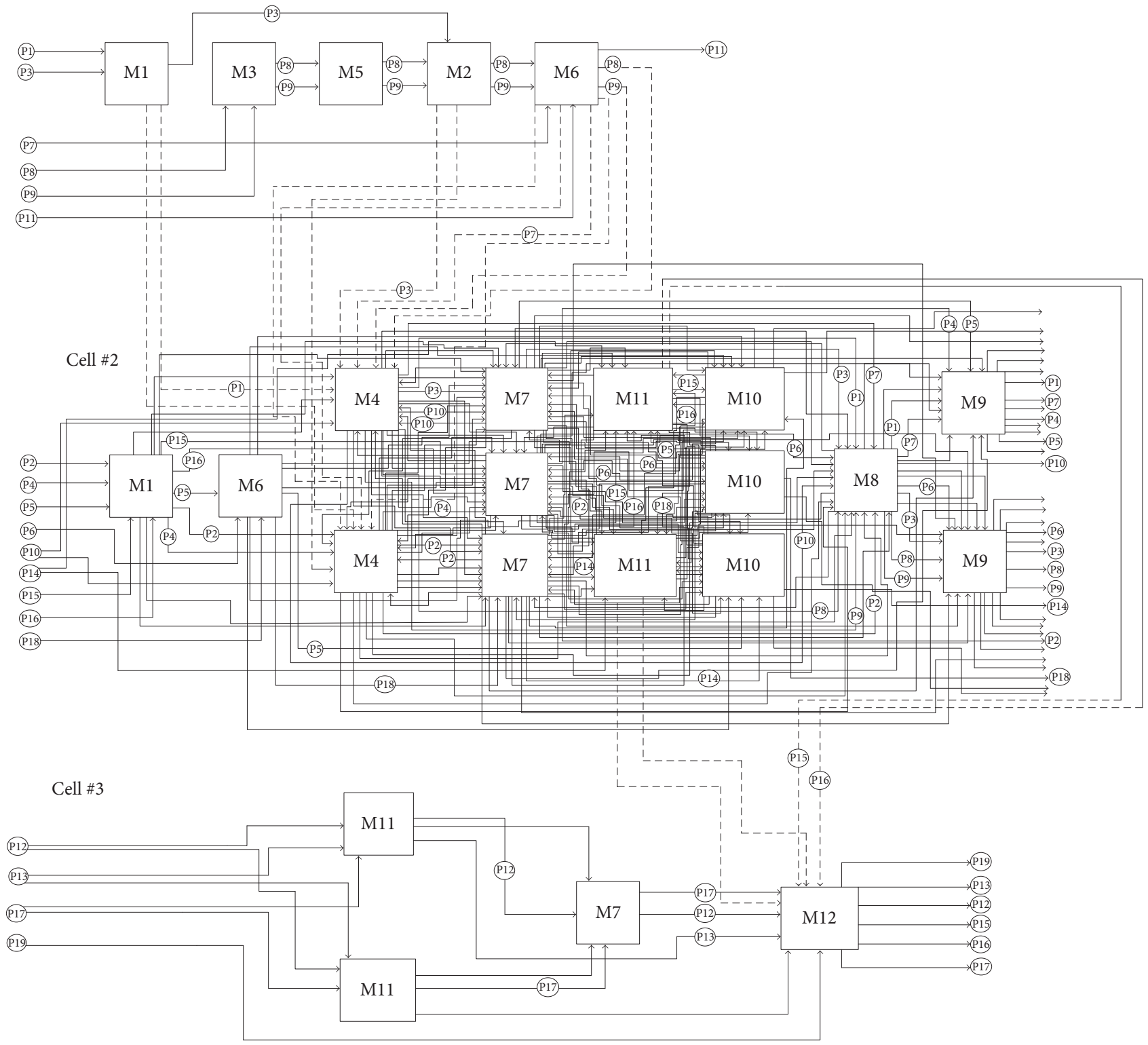

M Machine

(P) Part $\longrightarrow$ Intracell flows

$-\rightarrow$ IIntercell flows

FIGURE 13: MPC5 and its part flows divided into 3 cells.

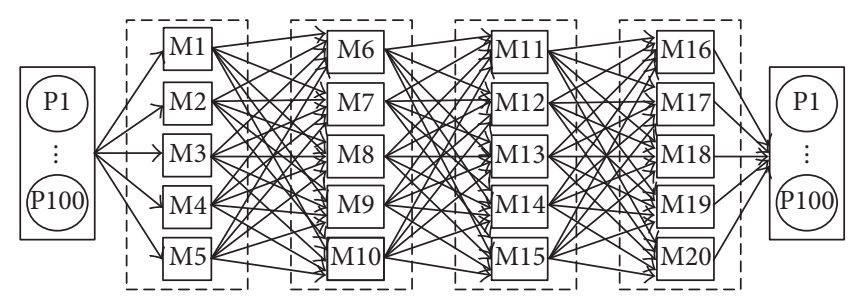

FIGURE 14: Job shop production with alternative part flows. 
TABLE 16: Comparison of indirect indicators with static complexity measure.

\begin{tabular}{lcccc}
\hline Layout \#1 & Static complexity & Production line balancing rate & Number of intercell flows & Number of intracell flows \\
\hline MPC1 & 47,8 bits & $92,4 \%$ & 15 & 244 \\
MPC2 & 50,7 bits & $78,7 \%$ & 0 & 262 \\
MPC3 & 53,9 bits & $78,2 \%$ & 8 & 326 \\
MPC4 & 44,8 bits & $85,6 \%$ & 6 & 141 \\
MPC5 & 47,1 bits & $50,7 \%$ & 14 & 217 \\
\hline
\end{tabular}
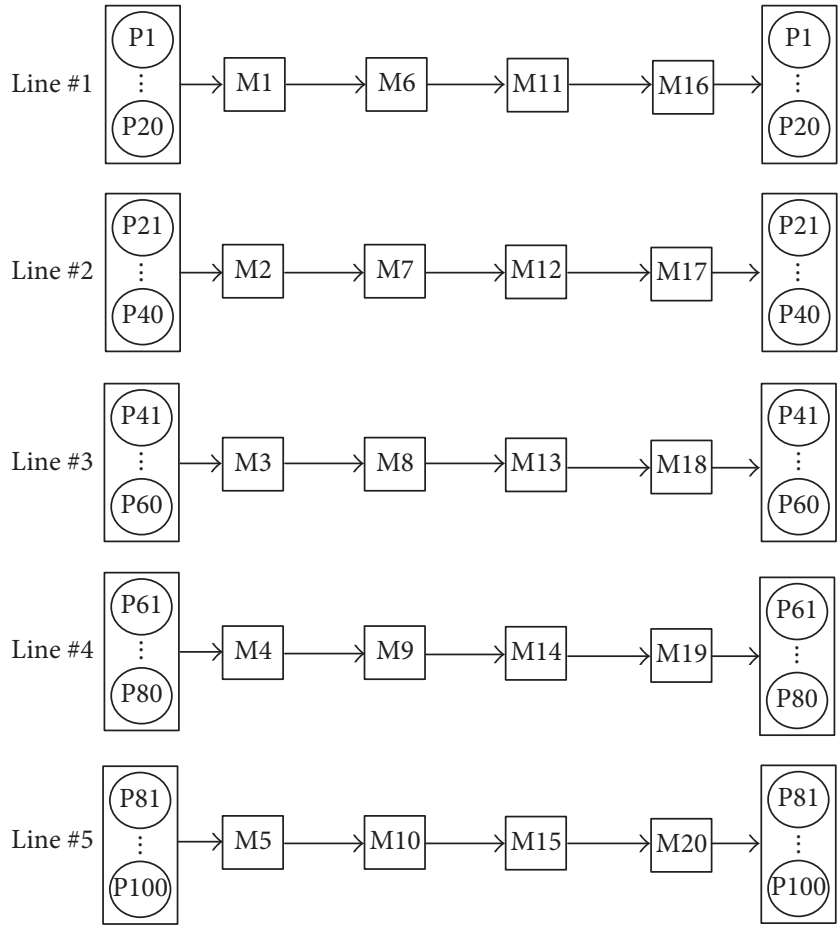

FIgURE 15: Flow shop production divided into 5 lines.

excluding one situation. It is specifically for number of intercell flows in MPC1, where the number of intercell flows should cause the highest complexity, but in this case the value of static complexity is the lowest.

It can be explained by the fact that it is the specific situation. The second line (cell) contains three machines of M10 type, while in the first line there is no machine of M10 type. But, this layout is the most preferable from the perspective of production line balancing rate.

\section{Conclusion}

The presented paper offers promising findings for improving the static complexity measurement and assessment of manufacturing systems. It was also proved that the four criteria defined for validation of static complexity have to be respected and we underline their importance for a future research focused on static complexity issues in manufacturing environment.

At the same time, it can be stated that indirect complexity indicators seem to be helpful tools to assess the property of manufacturing systems. It can be also anticipated that production line balancing rate more greatly affects the complexity mitigation, compared to number of intercell part flows and intracell part flows. Nonetheless, it will be necessary to go through a number of simulation experiments with different manufacturing systems to verify these prepropositions.

\section{Conflicts of Interest}

The authors declare that there are no conflicts of interest regarding the publication of this paper.

\section{Acknowledgments}

This paper has been supported by the Ministry of Education of the Slovak Republic (KEGA Project no. 078TUKE-4/2015) and is part of actual research activities in the project SME 4.0 (Industry 4.0 for SMEs) with funding received from the European Union's Horizon 2020 research and innovation program under the Marie Skłodowska-Curie Grant Agreement no. 734713 .

\section{References}

[1] T. Blecker, B. Kaluza, N. Abdelkafi, and G. Kreutler, "Mass customization vs. complexity: a Gordian knot?" in An Enterprise Odyssey. International Conference Proceedings, p. 890, University of Zagreb, Faculty of Economics and Business, 2004.

[2] K. K. B. Hon, "Performance and evaluation of manufacturing systems," CIRP Annals: Manufacturing Technology, vol. 54, no. 2, pp. 139-154, 2005.

[3] L. D. Fredendall and T. J. Gabriel, "Manufacturing complexity: a quantitative measure," in Proceedings of the POMS Conference, April 2003.

[4] F. Isik, "Complexity in supply chains: a new approach to quantitative measurement of the supply-chain-complexity," Supply Chain Management, pp. 417-432, 2011.

[5] G. D. M. Frizelle, "Getting the measure of complexity," Manufacturing Engineer, vol. 75, no. 6, pp. 268-270, 1996.

[6] W. W. Cooper, K. K. Sinha, and R. S. Sullivan, "Measuring complexity in high-technology manufacturing: indexes for evaluation," Interfaces, vol. 22, no. 4, pp. 38-48, 1992.

[7] N. Papakostas, K. Efthymiou, D. Mourtzis, and G. Chryssolouris, "Modelling the complexity of manufacturing systems using nonlinear dynamics approaches," CIRP Annals - Manufacturing Technology, vol. 58, no. 1, pp. 437-440, 2009.

[8] J. P. M. Schmitz, D. A. Van Beek, and J. E. Rooda, "Chaos in discrete production systems?" Journal of Manufacturing Systems, vol. 21, no. 3, pp. 236-245, 2002.

[9] V. Modrak, Ed., Mass Customized Manufacturing, CRC Press, Boca Raton, Fla, USA, 2016. 
[10] K. Efthymiou, A. Pagoropoulos, N. Papakostas, D. Mourtzis, and G. Chryssolouris, "Manufacturing systems complexity review: Challenges and outlook," in Proceedings of the 45th CIRP Conference on Manufacturing Systems, CMS 2012, pp. 644-649, May 2012.

[11] N.-P. Suh, Complexity, Theory and Applications, Oxford University Press, 2005.

[12] A. V. Deshmukh, J. J. Talavage, and M. M. Barash, "Complexity in manufacturing systems, Part 1: Analysis of static complexity," IIE Transactions (Institute of Industrial Engineers), vol. 30, no. 7, pp. 645-655, 1998.

[13] C. L. Magee and O. L. de Weck., An Attempt at Complex System Classification, Working Paper Series, Massachusetts Institute of Technology, Engineering Systems Division, 2002, ESD-WP2003-01.02-ESD Internal Symposium.

[14] G. J. Chaitin, Algorithmic Information Theory, Cambridge University Press, Cambridge, UK, 1987.

[15] M. Gell-Mann and S. Lloyd, "Information measures, effective complexity, and total information," Complexity, vol. 2, no. 1, pp. 44-52, 1996.

[16] N. P. Suh, A Theory of Complexity and Applications, Massachusetts Institute of Technology Cambridge, 2005.

[17] R. Clausius, "Ueber eine veränderte Form des zweiten Hauptsatzes der mechanischen Wärmetheorie," Annalen der Physik, vol. 169, no. 12, pp. 481-506, 1854.

[18] C. E. Shannon, "A mathematical theory of communication," The Bell System Technical Journal, vol. 27, pp. 379-423, 1948.

[19] G. Frizelle and E. Woodcock, "Measuring complexity as an aid to developing operational strategy," International Journal of Operations and Production Management, vol. 15, no. 5, pp. 2639, 1995.

[20] R. L. Flood and E. R. Carson, Dealing with Complexity: An Introduction to the Theory and Practice of Systems Science, Springer, Boston, Mass, USA, 1988.

[21] S. Lloyd and H. Pagels, "Complexity as thermodynamic depth," Annals of Physics, vol. 188, no. 1, pp. 186-213, 1988.

[22] N. P. Suh, "Theory of complexity, periodicity and the design axioms," Research in Engineering Design - Theory, Applications, and Concurrent Engineering, vol. 11, no. 2, pp. 116-131, 1999.

[23] G. Frizelle and H. Richards, "Tackling industrial complexity: the ideas that make a difference," in Proceedings of the 2nd International Conference of the Manufacturing Complexity Network, pp. 9-10, Cambridge, UK, 2002.

[24] H. Fujimoto, A. Ahmed, Y. Iidda, and M. Hanai, "Assembly process design for managing manufacturing complexities because of product varieties," International Journal of Flexible Manufacturing Systems, vol. 15, no. 4, pp. 283-357, 2003.

[25] S. J. Hu, X. Zhu, H. Wang, and Y. Koren, "Product variety and manufacturing complexity in assembly systems and supply chains," CIRP Annals - Manufacturing Technology, vol. 57, no. 1, pp. 45-48, 2008.

[26] H. Elmaraghy, T. Algeddawy, S. N. Samy, and V. Espinoza, "A model for assessing the layout structural complexity of manufacturing systems," Journal of Manufacturing Systems, vol. 33, no. 1, pp. 51-64, 2014.

[27] Z. Zhang, "Manufacturing complexity and its measurement based on entropy models," International Journal of Advanced Manufacturing Technology, vol. 62, no. 9-12, pp. 867-873, 2012.

[28] M. Fisher, J. Hammond, W. Obermeyer, and A. Raman, "Configuring a supply chain to reduce the cost of demand uncertainty," Production and Operations Management, vol. 6, no. 3, pp. 211225, 1997.
[29] S. Sivadasan, J. Efstathiou, G. Frizelle, R. Shirazi, and A. Calinescu, "An information-theoretic methodology for measuring the operational complexity of supplier-customer systems," International Journal of Operations and Production Management, vol. 22, no. 1, pp. 80-102, 2002.

[30] V. Deshmukh Abhijit, Complexity and chaos in manufacturing systems, Purdue University, 1993.

[31] F. Isik, "An entropy-based approach for measuring complexity in supply chains," International Journal of Production Research, vol. 48, no. 12, pp. 3681-3696, 2010.

[32] R. Mason-Jones and D. R. Towill, "Shrinking the Supply Chain Uncertainty Circle," Control-Institute of Operations Management, vol. 24, no. 7, pp. 17-22, 1998.

[33] H. Wildemann, Komplexitätsmanagement: Vertrieb, Produkte, Beschaffung, F\&E, Produktion, Administration, TCW Report, TCW Transfer-Centrum GmbH, Munich, Germany, 1st edition, 2000.

[34] T. Blecker, W. Kersten, and C. Meyer, "Development of an approach for analyzing supply chain complexity," in Mass Customization: Concepts-Tools-Realization, T. Blecker and G. Friedrich, Eds., p. 47, GITO Verlag, Berlin, Germany, 2005.

[35] S. Serdarasan, "A review of supply chain complexity drivers," Computers and Industrial Engineering, vol. 66, no. 3, pp. 533540, 2013.

[36] P. Anderson, "Complexity theory and organization science," Organization Science, vol. 10, no. 3, pp. 216-232, 1999.

[37] A. Calinescu, J. Efstathiou, L. H. Huatuco, and S. Sivadasan, "Classes of complexity in manufacturing," in Proceedings of the Advances in Manufacturing Technology-Conference, vol. 15, pp. 351-356, April 2001.

[38] S. M. Afazov, "Modelling and simulation of manufacturing process chains," CIRP Journal of Manufacturing Science and Technology, vol. 6, no. 1, pp. 70-77, 2013.

[39] Y. Kim and J. Lee, "Manufacturing strategy and production systems: an integrated framework," Journal of Operations Management, vol. 11, no. 1, pp. 3-15, 1993.

[40] S. Kotha and D. Orne, "Generic manufacturing strategies: a conceptual synthesis," Strategic Management Journal, vol. 10, no. 3, pp. 211-231, 1989.

[41] H. L. Lee and C. Billington, "The evolution of supply-chainmanagement models and practice at Hewlett-Packard," Interfaces, vol. 25, no. 5, pp. 42-63, 1995.

[42] Z. Zhang, "Modeling complexity of cellular manufacturing systems," Applied Mathematical Modelling, vol. 35, no. 9, pp. 4189-4195, 2011.

[43] L. Yan and S. A. Irani, "Classroom tutorial on the design of a cellular manufacturing system," Handbook of Cellular Manufacturing Systems, pp. 613-659, 1999.

[44] J. Rintanen, "Computational Complexity of Automated Planning and Scheduling," in Proceedings of the Twenty-Sixth International Conference on Automated Planning and Scheduling (ICAPS '16), pp. 12-17, London, UK, 2016.

[45] T. Morton and D. W. Pentico, Heuristic Scheduling Systems: With Applications to Production Systems and Project Management, vol. 3, John Wiley \& Sons, New York, NY, USA, 1993.

[46] X. Hu, Y. Zhang, N. Zeng, and D. Wang, "A novel assembly line balancing method based on PSO algorithm," Mathematical Problems in Engineering, vol. 2014, Article ID 743695, 2014.

[47] W. Bin, "Manufacturing and Supply Systems Management," in A Unified Framework of Systems Design and Operation, p. 540, Springer Science \& Business Media, 2012. 
[48] P. C. Kulkarni and K. Shanker, "A genetic algorithm for layout problems in cellular manufacturing systems," in Proceedings of the IEEE International Conference on Industrial Engineering and Engineering Management, IEEM 2007, pp. 694-698, December 2007.

[49] B. R. Sarker and J. A. Yu, "Two-phase procedure for duplicating bottleneck machines in a linear layout, cellular manufacturing system," International Journal of Production Research, vol. 32, no. 9, pp. 2049-2067, 1994.

[50] W. Chan, C. Chan, and W. Ip, "A heuristic algorithm for machine assignment in cellular layout," Computers \& Industrial Engineering, vol. 44, no. 1, pp. 49-73, 2003.

[51] S. Song, K. Hitomi, K. Hitomi, K. Hitomi, and K. Hitomi, "GT cell formation for minimizing the intercell parts flow," International Journal of Production Research, vol. 30, no. 12, pp. 27372753, 1992.

[52] N.-C. Wei and O. O. Mejabi, "A clustering approach for minimizing intercell trips in cell formation," Journal of Intelligent Manufacturing, vol. 19, no. 1, pp. 13-20, 2008.

[53] S. Wang and B. R. Sarker, "Locating cells with bottleneck machines in cellular manufacturing systems," International Journal of Production Research, vol. 40, no. 2, pp. 403-424, 2002.

[54] V. Modrák and R. S. Pandian, "Flow shop scheduling algorithm to minimize completion time for $\mathrm{n}$-jobs $\mathrm{m}$-machines problem," Tehnicki Vjesnik, vol. 17, no. 3, pp. 273-278, 2010.

[55] A. A. Klen Pereira, "Linking technology and people through virtual production areas," in Proceedings of the Third International Conference on Concurrent Engineering: Research and Applications, Toronto, Canada, August 1996. 


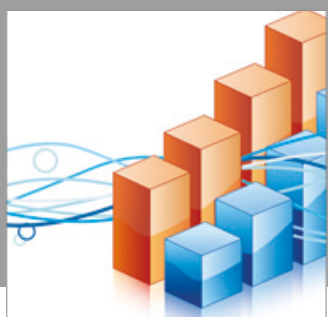

Advances in

Operations Research

vatersals

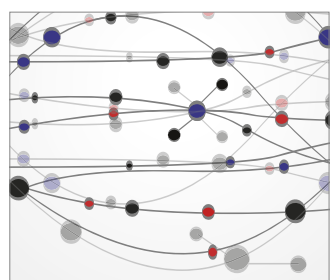

\section{The Scientific} World Journal
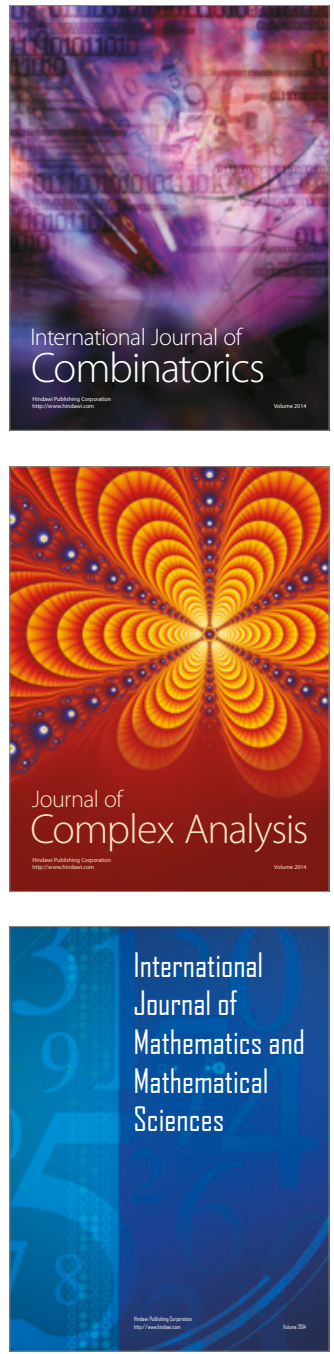
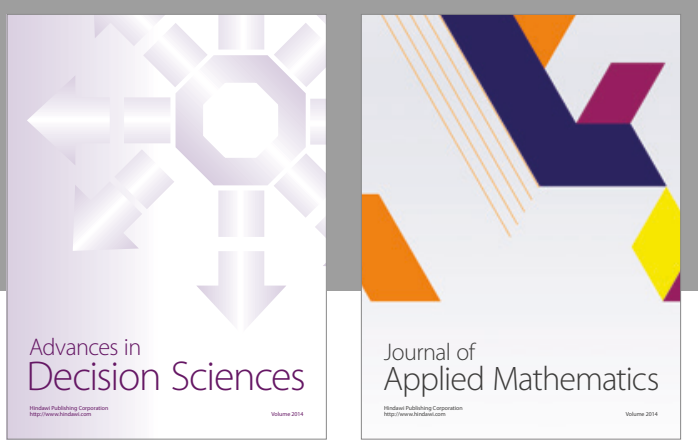

Algebra

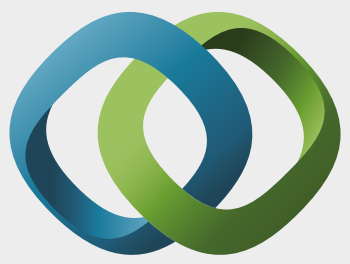

\section{Hindawi}

Submit your manuscripts at

https://www.hindawi.com
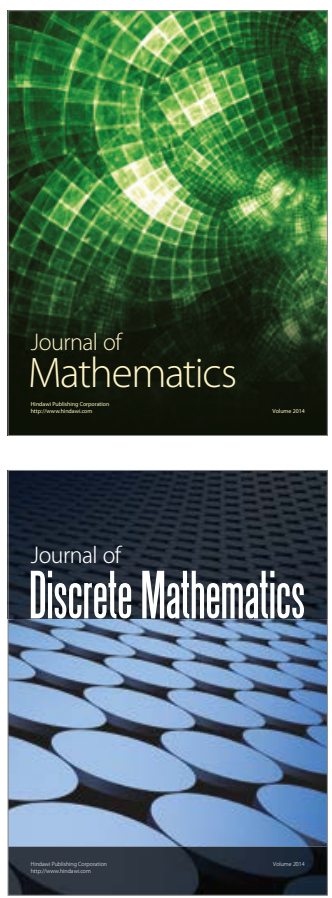

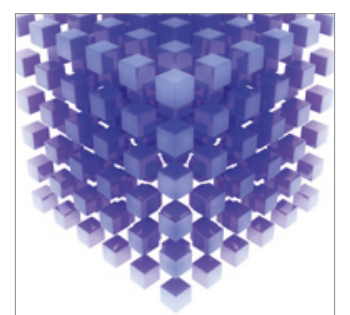

Mathematical Problems in Engineering
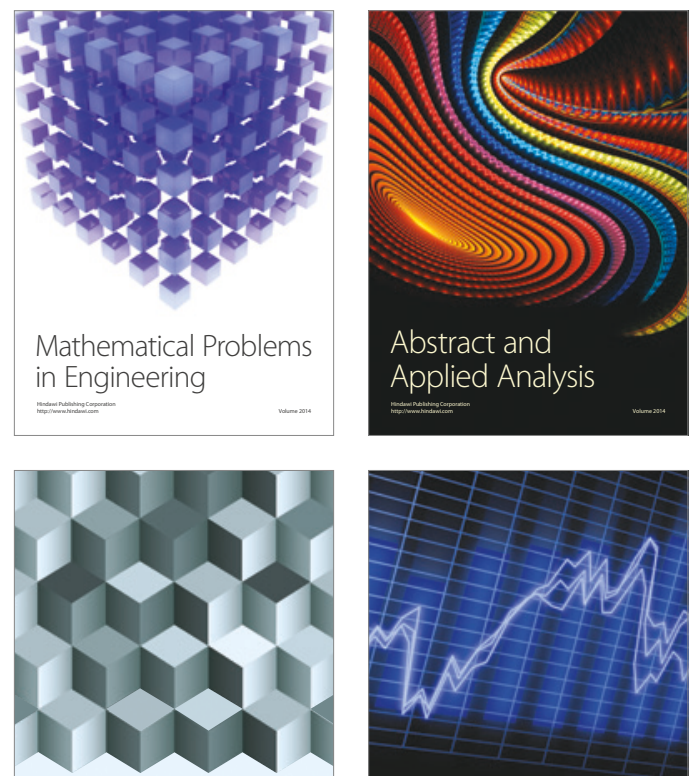

Journal of

Function Spaces

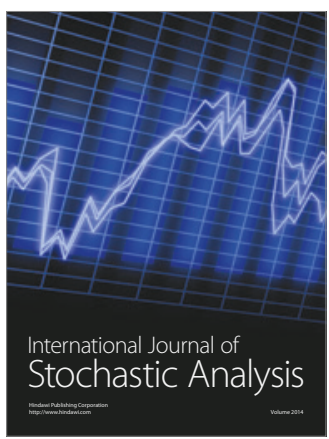

Probability and Statistics
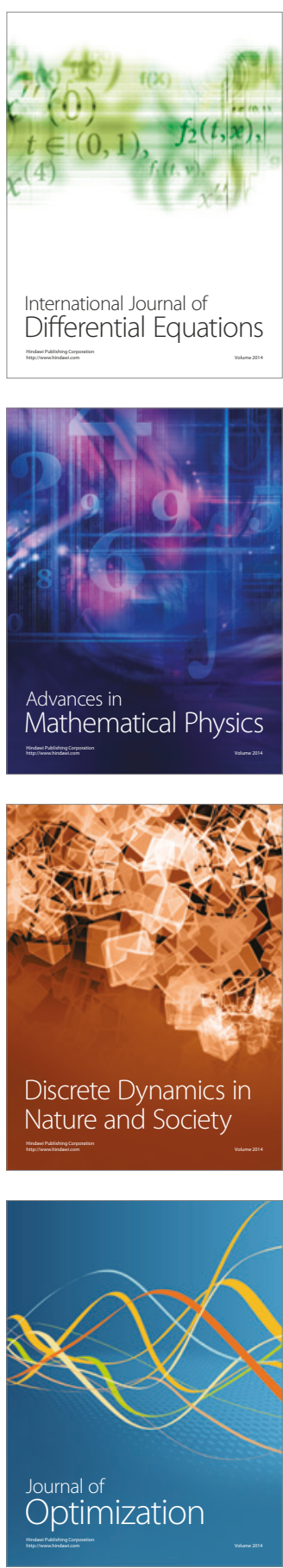